\title{
Measuring what matters to patients: using goal content to inform measure choice and development
}

\author{
Jenna Jacob (corresponding author) \\ Child Outcomes Research Consortium, Evidence Based Practice Unit, University College London and the Anna Freud \\ Centre, UK
}

\section{Julian Edbrooke-Childs}

Evidence Based Practice Unit, University College London and the Anna Freud Centre, UK

\section{Duncan Law}

London and South East CYP IAPT Learning Collaborative, hosted at the Anna Freud Centre, UK

\section{Miranda Wolpert}

Evidence Based Practice Unit, University College London and the Anna Freud Centre, UK

\section{Abstract}

Introduction: Personalised care requires personalised outcomes and ways of feeding back clinically useful information to clinicians and practitioners, but it is not clear how to best personalise outcome measurement and feedback using existing standardised outcome measures.

Method: The constant comparison method of grounded theory was used to compare goal themes derived from goals set at the outset of therapy for 180 children aged between 4 and 17 years, visiting 8 child and adolescent mental health services, to existing standardised outcome measures used as part of common national datasets.

Results: 20 out of 27 goal themes corresponded to items on at least one commonly used outcome measure.

Discussion: Consideration of goal themes helped to identify potential relevant outcome measures. However, there were several goal themes that were not captured by items on standardised outcome measures. These seemed to be related to existential factors such as understanding, thinking about oneself and future planning.

Conclusions: This presents a powerful framework for how clinicians can use goals to help select a standardised outcome measure (where this is helpful) in addition to the use of a goals based outcome measure and personalise choices. There may be areas not captured by standardised outcome measures that may be important for children and young people and which may only be currently captured in goal measurement. There is an indication that we may not be measuring what is important to children and young people. We may need to develop or look for new measures that capture these areas.

\section{Corresponding author:}

Jenna Jacob, Child Outcomes Research Consortium, Evidence Based Practice Unit, University College London and the Anna Freud Centre, 4-8 Rodney Street, London N1 9JH, UK.

Email: corc@annafreud.org 
Keywords: goals, goal setting, outcome measurement, feedback tools, child mental health and wellbeing, CAMHS, CORC

[Word count: 7,496]

\section{Introduction}

A recent review of Child and Adolescent Mental Health Services (CAMHS) in the United Kingdom (UK) highlighted several concerns related to a lack of appropriate funding and inadequate provision of services (House of Commons, 2014). In response, the children and young people's mental health and well-being taskforce has committed to build capacity within evidence-based, outcome-focused services by 2020 and published best practice guidelines, including the use of Routine Outcome Measures (ROMs) particularly those completed by young people and families themselves: Patient Reported Outcome Measures (PROMs) and Patient Reported Experience Measures (PREMs; Department of Health (DH), 2015).

PROMs and PREMS are questionnaires regularly administered to service users, from which healthcare professionals are able to collect treatment progress information (Carlier et al., 2012). PROMs have been widely used in services offering provision for emotional and wellbeing difficulties to young people across the UK and beyond for the past decade (Child Outcomes Research Consortium (CORC), 2015; Fleming, Jones, Bradley \& Wolpert, 2014; and Children and Young People's Improving Access to Psychological Therapies (CYP IAPT), Law \& Wolpert, 2014). There are a number of standardised PROMs available, which span clinician-identified presenting difficulties and population groups. The information from these questionnaires is used for two primary purposes: to evidence the impact of a treatment and for service evaluation $(\mathrm{DH}, 2010)$. Here, the tools are largely used for operational and management tasks. The second purpose is use as clinical tools that can help facilitate better collaborative practice, to open up discussions about how a young person or family sees progress and their experiences of the work with the practitioner (Law \& Wolpert, 2014). In the former use of these tools, they are labelled 'outcome measures' and in the latter they are 'clinical feedback tools'. In other countries (e.g., North America) tailoring not only the target of treatment but also the tools used to track progress is established (Weisz et al., 2011). The aim of the present research was to explore the feasibility of using goals to target the choice of standardised tools for tracking the progress of treatment in the UK, thereby supporting personalised outcome measurement and care. 
Research has shown the use of these tools can prove beneficial for young people with emotional and behaviour difficulties; including increased retention (Hawley \& Weisz, 2005; Lambert et al., 2003), better outcomes (Bickman, Kelley, Breda, de Andrade \& Riemer, 2011; Lambert, 2010; Shimokawa, Lambert \& Smart, 2010), and faster improvement (Bickman et al., 2011; de Jong, van Sluis, Nugter, Heiser, \& Spinhoven, 2012). Evidence suggests that clinical judgement alone may be less reliable for noting when a young person is not responding to treatment as expected (Hannan et al., 2005). The use of feedback tools counterbalances this by creating more tangible evidence to discuss difficulties and options for an agreed way forward: "Without direct feedback on how their clients are progressing, clinicians are essentially wearing a blindfold while shooting at a target," (Sapyta, Riemer \& Bickman, 2005; pp.152-153). Standardised tools may provide additional clinical information that may have otherwise been missed (Worthen \& Lambert, 2007). If the tools are used clinically in this way, the information provided can also be used to monitor outcomes and in most cases the same tools can be used to serve both purposes.

While there are many benefits to using standardised tools, numerous challenges to their use have also been documented (Badham 2011; Batty et al. 2012; Boswell et al. 2013; de Jong 2014; Edbrooke-Childs et al. 2014; Hall et al., 2014; Moran et al. 2012; Wolpert, 2013), specifically related to three broad areas: the content of standardised tools, the process of using tools, and the effective use of data derived from tools (Wolpert, Curtis-Tyler \& Edbrooke-Childs, 2014). Learning collaboratives such as CORC (Fleming et al., 2014; CORC, 2015) and CYP IAPT (Law \& Wolpert, 2014) work with services and clinicians to mitigate barriers and to encourage the meaningful use of the information from these tools at a clinical and service level (MINDFUL approach; Wolpert et al., 2014).

Barriers often relate to striking a balance between the need for generalisable evidence and providing personalised care (Wolpert, 2013).The advantages of idiographic measures (measures with an individual focus such as goal-based tools, e.g. GBOs; Law \& Jacob, 2015) and standardised tools to measure outcomes and gain feedback (e.g. broad symptom or wellbeing measures) have been explored elsewhere (Wolpert et al., 2012¹, 2014; Edbrooke-Childs et al, 2015). One key risk of harm is tools becoming a bureaucratic tick-box exercise if they are not seen as clinically meaningful by clinicians or young people (Badham, 2011; Wolpert, Fugard, Deighton \& Görzig, 2012).

While standardised tools are useful to gather information to create norms and benchmark at an aggregate level, evidence suggests that they may be less clinically meaningful to inform practice and lack a person-centred focus (Bromley \& Westwood, 2013; Norman, Dean, Hansford, \& Ford, 2013; Ruble, McGrew, \& Toland, 2012). In particular, clinicians have 
Measuring what matters to patients: using goal content to inform measure choice and development

referred to standardised tools as at times being depersonalising and too focused on numbers, calling for more individualised measurement (Norman et al., 2014). Mental health and wellbeing difficulties are individual; feedback from young people has highlighted the importance of treating patients as individuals and not simply reducing them to a score on a questionnaire (Badham, 2011). Drawing on social validation theory for service users to engage and be satisfied with care, they should experience the focus of treatment, techniques, and effects personally meaningful to them (Kazdin, 1977). This tension suggests that there is a call for outcome measurement in areas that are not covered by standardised tools, due to the concern that a focus on standardised tools alone may miss areas not included on these tools and may also distort clinical conversations to fit with questionnaire items rather than clinical presentations. Ensuring outcome measurement occurs within a personalised care context, and that we are therefore measuring what matters to patients, is a priority.

Personalised care is a key domain of healthcare quality (DH, 2011; IOM, 2001) and is increasingly seen as sitting at the heart of service models, with a call for greater alignment between patients' preferences, research evidence, and clinical experience and judgement (Frueh, Ford, Elhai \& Grubaugh, 2012). It involves putting service users at the centre of all decisions about their care, with choice and control based on a collaborative perspective (Health Foundation, 2015). Evidence suggests that young people have the capacity to be involved in treatment decisions, which may have benefits to self-esteem and the transition to adulthood (Alderson, Sutcliffe, \& Curtis, 2006; Costello, 2003; Huffine, 2005). Young people want to be involved in decisions about their treatment (Alderson et al., 2006; Coyne, 2006; Dogra, 2005; Kelsey, AbelsonMitchell, \& Skirton, 2007) and report feeling under-empowered when they have limited involvement (Gyamfi, KeensDouglas, \& Medin, 2007). For example, young people in acute care settings report feeling alienated when clinicians speak only to their parents and that a lack of communication is a barrier to personalised care (O'Brien, Crickard, Rapp, Holmes, \& McDonald, 2011). Studies in child mental health settings have found that interventions that include personalised care improve communication and treatment outcome (Asarnow et al., 2009; Westermann, Verheij, Winkens, Verhulst, \& Van Oort, 2013). There is an increasing commitment to embedding personalised care in CAMHS (Richter, Halliday, Grømer, \& Dybdahl, 2009; Soffe, Read, \& Frude, 2004).

DH (2015) recommended a move away from the tiered model of CAMHS, which no longer fits well with the evolving support young people and families seek, receive, or need. The THRIVE model (Wolpert et al., 2014) conceptualises a better approach to organising care, support and personalised care in CAMHS. The model proposes the use of idiographic measures, such as goal setting, to help work towards personalised care and "goal focused, evidence informed and 
outcomes focused intervention," (Wolpert et al., 2014, p. 7). The use of goal setting to direct interventions and outcome measurement may promote personalised care.

Goal setting and tracking has been used in CAMHS, often referred to as expectations, aims, or top problems, for many years (Kiresuk \& Sherman, 1968; Weisz et al., 2011, Bradley et al., 2013). Some types of mental health treatment concentrate on self-reflection, incorporating identifying and working collaboratively towards goals; for example, psychoanalysis (Gollwitzer \& Moskowitz, 1996) and its derivatives (e.g. CBT; Beck, 1997) and family therapy, (Diamond, Liddle, Hogue \& Dakof, 1999). Additionally, training programmes often have objectives or goals for parents to seek to achieve by the end of the course (Reid, Webster-Stratton \& Beauchaine, 2001). Although setting and tracking goals in therapy has been used for some time, systematically tracking goals as an outcome or feedback tool is a more recent venture.

A focus on agreed goals is often cited as a key component of personalised care, which has been advocated by service users (Chewning et al., 2013) and has also been shown to be an important driver of both positive therapeutic relationships and outcomes (Cooper, 2008). Goal setting as a method to track clinical progress has good face validity whereby young people and clinicians have attested to goal setting helping them to focus and progress treatment (Bromley \& Westwood., 2013; Emanuel et al., 2013; Law \& Wolpert, 2014; Pender et al., 2013) with mental health service users placing high value in working towards their own goals (Liberman and Kopelowicz, 2002).

The method of goal-based outcomes sits well in personalised care as the clinician and service user collaboratively discuss and choose the goals they want to work towards throughout treatment. A focus on what is central to what the individual wants to achieve moves away from the suggested tick-box exercise nature of some other methods of standardised outcome measurement (Badham, 2011; Wolpert et al., 2012). In particular, goal formulation may help to identify the target for intervention and correspondingly, areas of difficulties to assess and track using standardised tools. Clinicians may not want to use standardised tools that are not perceived to have clinical relevance and they may have low levels of self-efficacy in choosing and using tools (Edbrooke-Childs et al., 2014; Fleming et al., 2014; Norman et al., 2014).

There is an array of standardised tools from which clinicians can choose (CYP IAPT data spec; CORC, 2015). This may enable measures to be chosen that best meet patient preferences and presenting difficulties (Law \& Wolpert, 2014). However, it may require clinicians to be trained in a greater number of measures so they can quickly identify the right 
measure for the patient; this may be particularly problematic as evidence suggests that young people, parents, and clinicians may have different perceptions of reasons for attending services (Yeh \& Weisz, 2001).

Goal setting as a method of tracking outcomes also addresses some of the challenges discussed; for example, goals capture the individual nature of what someone wants to work on. This is counterbalanced by a lack of norms available and goals are not easily comparable between people due to the individualistic nature of goals. However, evidence suggests that goal scores may show more change over the course of therapy than standardised measures of psychosocial difficulties and impact on daily life (Edbrooke-Childs et al, 2015). Evidence has also shown that goal commitment is higher for existential goals (Riemer \& Bickman, 2011). Such goals were found to be prevalent in routinely collected data from services providing mental health provision to young people and their families (Jacob et al., 2015). This also suggested that goal setting in CAMHS may offer insight into areas of change related to distal factors such as understanding, confidence, and coping that are not explored by other standardised measures (Jacob et al., 2015) especially where difficulties are not expected to vastly improve in terms of symptomology (Batty et al., 2012). To service users, a good outcome has been shown to constitute something that was not a tick-box exercise and was meaningful to everyday life and to clinicians; as something that needs to be meaningful to the individual, it may be different to each patient. As part of this, empowerment and self-efficacy were identified as key areas of measurement not currently appropriately captured by existing tools (Childs, Deighton \& Wolpert, 2013). Evidence also suggests that goals may capture these important areas to young people, parents, and clinicians not covered by standardised tools. For instance, children set goals around ability to cope with emotional and behavioural difficulties (Bradley et al., 2013), which may differ to constructs such as coping with stress (Causey, \& Dubow, 1992) or resilience (Windle, Bennett, \& Noyes, 2011) captured in existing questionnaires.

Work on needs-based groupings in child and adolescent mental health supports this by suggesting a move away from assigning children to fixed, prescribed treatment pathways towards a shared formulation decided upon through a collaborative discussion, shared goals, and outcomes (Wolpert et al., 2015). The suggestion is that outcome measurement is chosen in line with the agreed focus of treatment. In an example given of a boy whose difficulties related to being anxious in social situations, the agreed way forward through collaborative discussions may be to work on a goal of spending more time with friends (the outcome important to him) alongside tracking anxiety (the symptom important to him) on a standardised outcome measure: see table 1 (taken from Wolpert et al., 2015; p.16.)

Table 1. Needs-based grouping and outcome indicator choices: some brief worked examples 


\begin{tabular}{|c|c|c|c|c|c|c|}
\hline Basic info & $\begin{array}{c}\text { Key problems } \\
\text { identified in } \\
\text { Current View Tool }\end{array}$ & $\begin{array}{l}\text { Needs-based } \\
\text { grouping } \\
\text { suggested by the } \\
\text { algorithm }\end{array}$ & $\begin{array}{l}\text { Collaborative consideration of choices in terms of needs- } \\
\text { based groupings and specific approaches within these }\end{array}$ & $\begin{array}{l}\text { Outcome indicators } \\
\text { chosen }\end{array}$ & $\begin{array}{l}\text { Needs-based } \\
\text { grouping assigned } \\
\text { following shared } \\
\text { decision making }\end{array}$ & $\begin{array}{l}\text { Agreement } \\
\text { with } \\
\text { algorithm's } \\
\text { suggestion? }\end{array}$ \\
\hline \begin{tabular}{l|} 
Boy \\
15 years old \\
Seen without \\
parents \\
though with \\
parental \\
knowledge \\
\end{tabular} & $\begin{array}{l}\text { Anxious in social } \\
\text { situations: } \\
\text { 'moderate' }\end{array}$ & \begin{tabular}{l|} 
Getting Help: Social \\
Anxiety Disorder \\
(Guided by NIIE \\
Guideline 159)
\end{tabular} & $\begin{array}{l}\text { Practitioner and young person discuss the effect of the anxious } \\
\text { feelings on social activities. A goal of spending more time with } \\
\text { friends is agreed. The options of either individual or group CBT } \\
\text { are considered and the pros and cons of involving parents, and } \\
\text { the decision is made to try } 8 \text { sessions of individual CBT, without } \\
\text { involving parents. }\end{array}$ & $\begin{array}{l}\text { Goals Based Outcome: } \\
\text { spend more time with } \\
\text { friends } \\
\text { Social Anxiety subscale } \\
\text { of Revised Child Anxiety } \\
\text { and Depression Scale } \\
\text { (RCADS) }\end{array}$ & $\begin{array}{l}\text { Getting Help: Social } \\
\text { Anxiety Disorder } \\
\text { (Guided by NIIE } \\
\text { Guideline 159) }\end{array}$ & Yes \\
\hline $\begin{array}{l}\text { Girl } \\
5 \text { years old } \\
\text { Two } \\
\text { biological } \\
\text { parents seen }\end{array}$ & $\begin{array}{l}\text { Carer management } \\
\text { of CYP behaviour: } \\
\text { 'moderate' } \\
\text { Difficulties sitting still } \\
\text { or concentrating: } \\
\text { 'mild' } \\
\begin{array}{l}\text { Peer relationship } \\
\text { difficulties: 'mild' }\end{array} \\
\end{array}$ & $\begin{array}{l}\text { Getting Advice: } \\
\text { Signposting and } \\
\text { Self-management } \\
\text { Advice (NICE } \\
\text { Guidance as } \\
\text { Relevant) }\end{array}$ & $\begin{array}{l}\text { Parents are finding it hard to manage their child's frequent } \\
\text { tantrums, and would like to cope better with these. Potential } \\
\text { participation in a parenting group is discussed, and the parents } \\
\text { think attendance would be difficult given their work and home } \\
\text { commitments. They are happy to get advice and signposting } \\
\text { towards relevant factsheets and websites. Advice for the child's } \\
\text { teacher is also offered. }\end{array}$ & $\begin{array}{l}\text { Experience of Service } \\
\text { Questionnaire (ESQ)- } \\
\text { satisfaction with advice } \\
\text { received }\end{array}$ & $\begin{array}{l}\text { Getting Advice: } \\
\text { Signposting and } \\
\text { Self-management } \\
\text { Advice (NICE } \\
\text { Guidance as } \\
\text { Relevant) }\end{array}$ & Yes \\
\hline $\begin{array}{l}\text { Boy } \\
11 \text { years old } \\
\text { Foster } \\
\text { parents }\end{array}$ & $\begin{array}{l}\text { Behavioural } \\
\text { difficulties: } \\
\text { 'moderate' } \\
\text { Anxious generally: } \\
\text { 'moderate' }\end{array}$ & \begin{tabular}{|l} 
Getting Help: Co- \\
occurring \\
Behavioural and \\
Emotional Difficulties \\
(NICE Guidance as \\
Relevant)
\end{tabular} & $\begin{array}{l}\text { Clinician and foster parents consider that the primary } \\
\text { intervention should target the extemalising behaviours, as the } \\
\text { child does not wish to engage with individual sessions on } \\
\text { anxiety. The foster parents see merit in attending a Webster- } \\
\text { Stratton parenting group and working with the clinician and } \\
\text { school to manage their child's frequent exclusion from class, } \\
\text { the reduction of which was a goal agreed by both child and } \\
\text { parents. }\end{array}$ & $\begin{array}{l}\text { Goals Based Outcome: } \\
\text { increase number of } \\
\text { days per week when no } \\
\text { exclusions from class } \\
\text { Brief Parental Self- } \\
\text { Efficacy Scale (BPSES) } \\
\text { No of days when } \\
\text { excluded from class }\end{array}$ & $\begin{array}{l}\text { Getting Help: } \\
\text { Behavioural and/or } \\
\text { Conduct Disorders } \\
\text { (Guided by NICE } \\
\text { Guideline 158) }\end{array}$ & No \\
\hline $\begin{array}{l}\text { Girl } \\
14 \text { years old } \\
\text { Mother and } \\
\text { step father }\end{array}$ & $\begin{array}{l}\text { Self-Harm: } \\
\text { 'moderate' }\end{array}$ & $\begin{array}{l}\text { Getting Help: Self- } \\
\text { harm (Guided by } \\
\text { NICE Guidelines } 16 \\
\text { and/or 133) }\end{array}$ & $\begin{array}{l}\text { Young person unwilling to engage in treatment and together } \\
\text { with carers agrees a plan to safely manage self-harm. Follow- } \\
\text { up appointment and advice to mother and step father is offered. } \\
\text { The young person agrees to a meeting with an identified } \\
\text { member of school staff and the clinician to discuss how the } \\
\text { safety plan might be implemented at school, where peer conflict } \\
\text { seems to be a common trigger for the young person's distress. }\end{array}$ & $\begin{array}{l}\text { Experience of Service } \\
\text { Questionnaire (ESQ)- } \\
\text { satisfaction with advice } \\
\text { received }\end{array}$ & $\begin{array}{l}\text { Getting Advice: } \\
\text { Signposting and } \\
\text { Self-management } \\
\text { Advice (NICE } \\
\text { Guidance as } \\
\text { Relevant) }\end{array}$ & No \\
\hline
\end{tabular}

The aim of this research was to build on themes derived from goals set by young people, parents, and clinicians at the outset of therapy (Bradley et al., 2013; Jacob et al., 2015) to explore the feasibility of using goals to inform not only the target of treatment but also the target of tracking the progress of treatment, thereby supporting personalised outcome measurement and care. Two research questions were examined:

1. Can goal content be used to shape outcome and feedback tool choices?

2. Are there goal themes not captured by standardised outcome and feedback tools?

\section{Method}

The present research involved secondary analysis of data derived from a dataset comprising 933 goals set at the outset of therapy for 180 children and young people aged between 4 and 17 years, who were seen by 8 child and adolescent mental health services between 2007 and 2010. The goals data were collected routinely as part of ongoing practice by clinicians and others offering provision for children and young people with mental health and wellbeing difficulties and their families. All members of a learning collaboration focused on improving provision through the appropriate use of outcome information were invited to submit the descriptive content of their recorded goals for research purposes. The goals data received were collated for analysis. Each of the 8 services that provided data were required to follow their own ethical guidelines as advised by their information governance team; no other ethical permission was required for this research as it involved secondary analysis of routinely collected data (NHS, 2015). 
Goal themes were taken from previous research (Bradley et al., 2013 \& Jacob et al., 2015) whereby three (child-led, parentled, and jointly agreed) goal frameworks were created by an iterative process of thematic analysis (Braun and Clarke, 2006), also drawing on an existing framework of goals derived from psychotherapy research (Grosse Holtforth \& Grawe 2002). This research demonstrated through axial coding that all goal themes that emerged from the child-led framework mapped onto themes from the other perspectives (parent-led and jointly agreed). However, there were themes that emerged from the parent-led and jointly agreed goal frameworks that were not present in the child-led data; i.e. (parent) co-operation, being calmer and inappropriate behaviour and (jointly agreed) family support and guidance. An amalgamated version of the childled, parent-led, and jointly agreed goal frameworks was created, with outstanding themes from the parent-led and jointly agreed goals included in and referenced as such (Jacob et al., 2015) this version was used for the present analysis.

\section{Analytic strategy}

The items from a set of standardised feedback tools and outcome tools (questionnaires) widely used in UK CAMHS (CORC, 2015; see appendix for a complete list) were selected for coding, comprising 192 items in total. Two coders (J.J. \& M.W.) coded items from the standardised questionnaires using the amalgamated goal themes from previously published studies of child-rated, parent-rated, and jointly agreed goals as described above (Bradley et al., 2013; Jacob et al., 2015) using the constant comparative method of grounded theory (Glaser \& Strauss, 1967) with selective coding (Corbin \& Strauss, 1990). This iterative process involved the coders first analysing which goal theme code(s) applied to each questionnaire item separately before meeting to compare and integrate any differences in coding. For example, the goal theme 'co-operation' could be mapped onto questionnaire items on measures about behavioural difficulties (ODDp ("My child actively defies or refuses to comply with adults' requests or rules", "My child argues with adults") and SDQ ("Generally obedient, usually does what adults request')). Codes for individual items were then aggregated for each questionnaire subscale (in the example given, the SDQ conduct subscale); the relevant codes for the subscale items are reported in Table 2 (appendix).

\section{Results}

Overall, 20 out of the 27 goal themes had corresponding items on at least one of 13 commonly used standardised outcome/feedback tools. See Figures 1-4 for a full breakdown.

Of the 27 goal themes explored, 7 did not correspond to any item on the standardised outcome and feedback tools considered:

1. Talk about feelings and thoughts 
2. Letting people know what help I need

3. Understanding my anger

4. I would like to...(goals with personal meaning or related to a hobby)

5. To be more responsible for myself (including care of myself) or to be more independent

6. Feeling more confident or feeling better within myself

7. Thinking about me and understanding my past

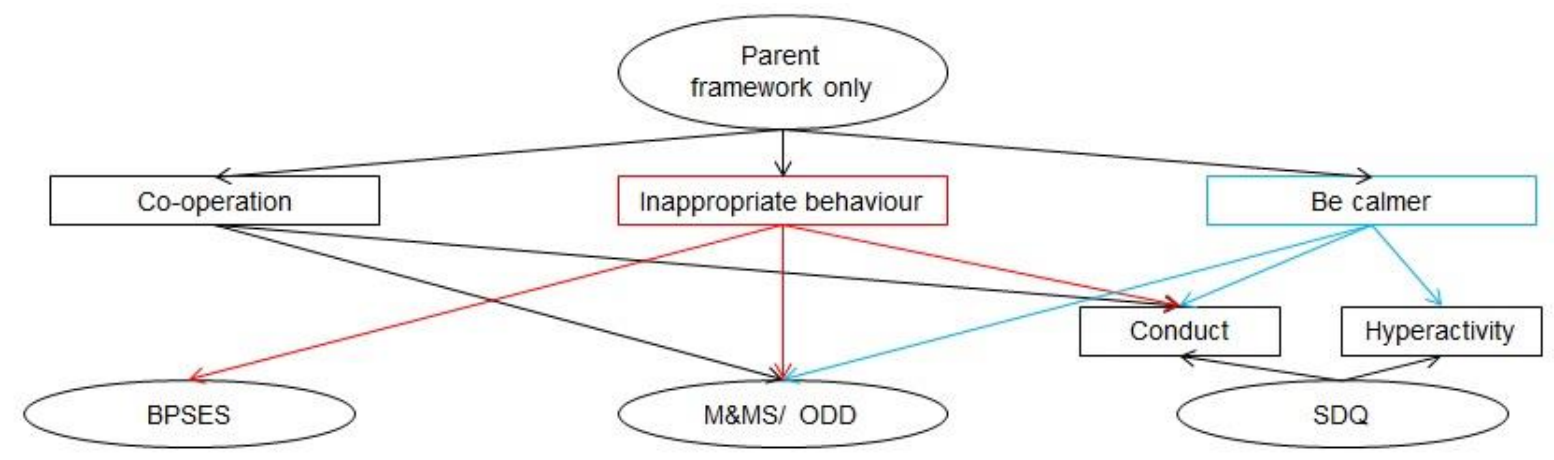

Figure 1: Parent framework goal themes mapped to corresponding items on standardised tools

Figure 1 demonstrates that from goal themes that were derived from parent-led goals only, themes related to 'co-operation', 'inappropriate behaviour' and 'being calmer' mapped to items on standardised tools focused on parental self-efficacy (BPSES; inappropriate behaviour); behaviour management and conduct (M\&MS, ODDp, SDQ conduct subscale; cooperation, be calmer, co-operation, inappropriate behaviour) and hyperactivity (SDQ hyperactivity subscale; be calmer).

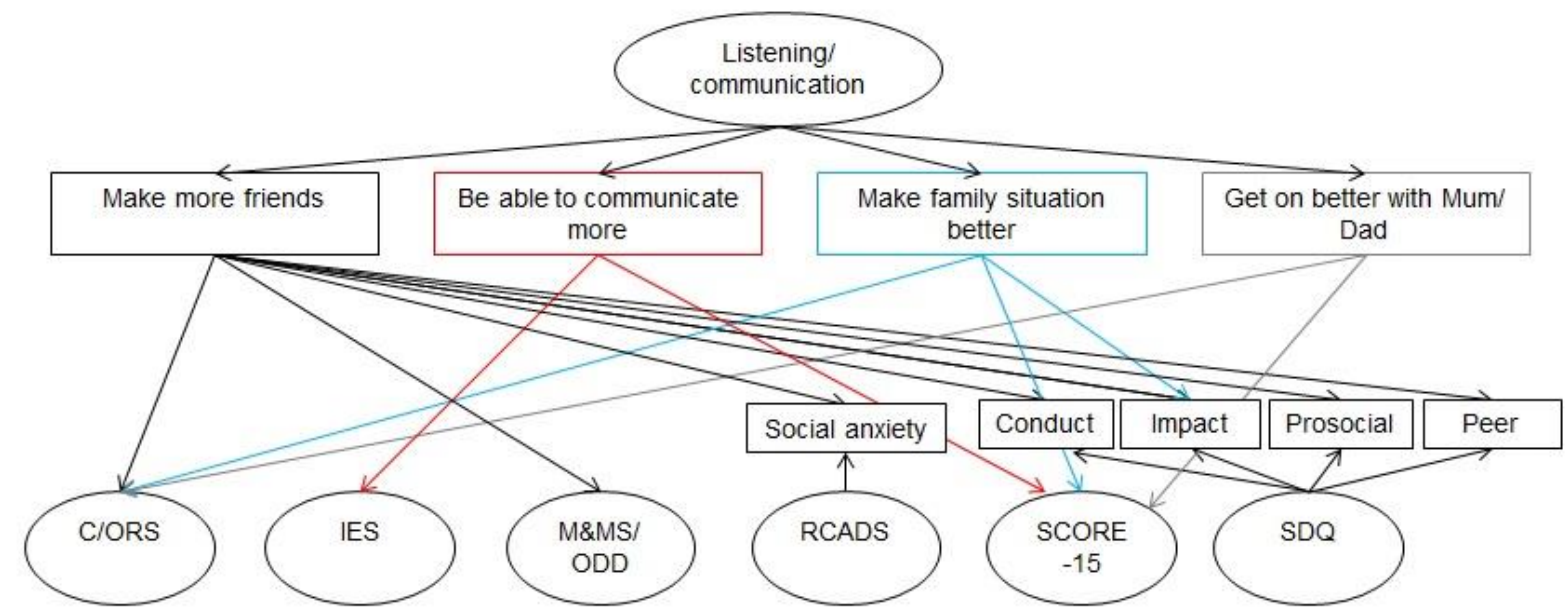

Figure 2: Listening and communication goal themes mapped to corresponding items on standardised tools 
Figure 2 demonstrates that from goal themes derived from all perspectives, themes related to listening and communication mapped to items on standardised tools focused on general wellbeing (CORS, SDQ impact subscale, make more friends, make family situation better, get on better with mum/dad); impact of events (PTSD; IES scale; be able to communicate more); behaviour management and conduct (M\&MS, ODDp, SDQ conduct subscale; make more friends); social anxiety (RCADS subscale; make more friends); family functioning (SCORE-15; be able to communicate more; make family situation better; get on better with mum/dad); and prosocial and peer (SDQ subscales; make more friends).

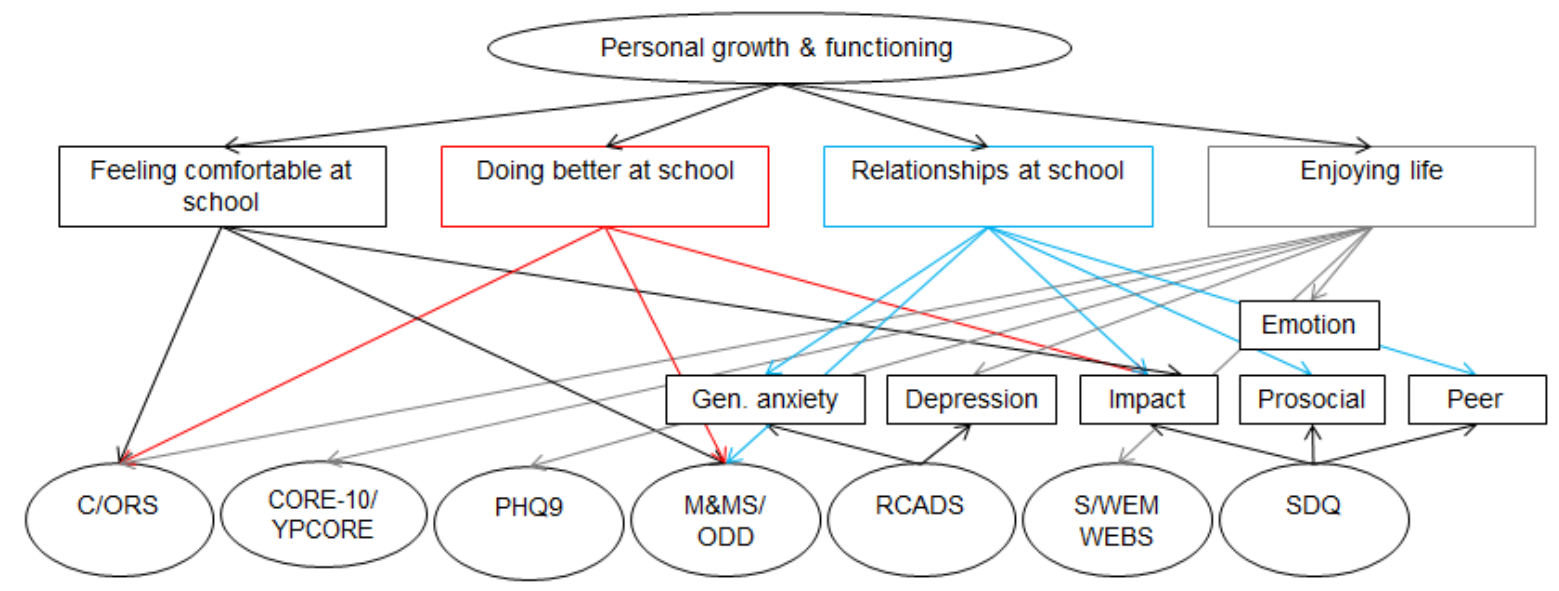

Figure 3: Personal growth \& functioning goal themes mapped to corresponding items on standardised tools

Figure 3 demonstrates that from goal themes derived from all perspectives, themes related to personal growth and functioning mapped to items on standardised tools focused on general wellbeing (CORS, SDQ impact subscale, CORE10/YP CORE, S/WEMWBS; feeling comfortable at school, doing better at school, enjoying life); depression (PHQ-9, RCADS subscale, SDQ emotional subscale; enjoying life); behaviour management and conduct (M\&MS, ODDp; feeling comfortable at school, doing better at school, relationships at school); general anxiety (RCADS subscale; relationships at school) and prosocial and peer (SDQ subscales; relationships at school).

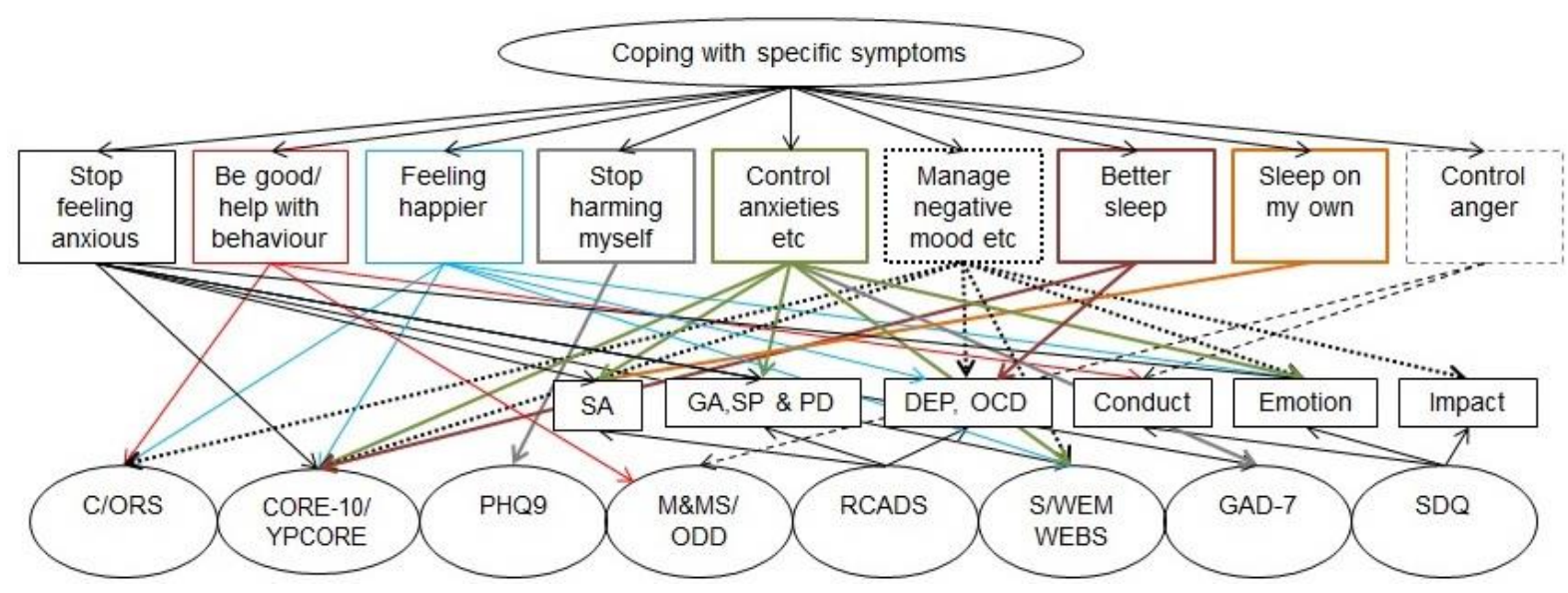




\section{Figure 4: Coping with specific symptoms goal themes mapped to corresponding items on standardised tools}

Figure 4 demonstrates that from goal themes derived from all perspectives, themes related to coping with specific symptoms mapped to items on standardised tools focused on general wellbeing (CORS, SDQ impact subscale,CORE-10/YP CORE, S/WEMWBS; manage negative mood and negative thoughts and feelings or patterns, be good/help with behaviour, feel happier; control and manage anxiety, worries, stop feeling anxious, stressed, worried, be good/ help with behaviour, better sleep); depression (PHQ-9, RCADS subscale, SDQ emotional subscale; manage negative mood and negative thoughts and feelings or patterns, better sleep, feel happier, stop harming myself); behaviour management and conduct (M\&MS, ODDp; controlling and managing my anger); anxiety (RCADS social anxiety, general anxiety, social phobia and panic subscales; SDQ emotional subscale; GAD-7; control and manage anxiety, worries, stop feeling anxious, stressed, worried, sleep on my own); OCD (RCADS subscale; manage negative mood and negative thoughts and feelings or patterns); and prosocial and peer difficulties (SDQ subscales; relationships at school).

\section{Discussion}

The aim of this research was to build on previous themes derived from goals set by young people, parents, and clinicians at the outset of therapy (Bradley et al., 2013; Jacob et al., 2015) to explore the feasibility of using goals to inform both the target of and tracking of the progress of treatment, thereby supporting personalised outcome measurement and care. Some areas were debated by the two coders. For example, the SWEMWBS item "'ve been able to make up my own mind about things" was considered a potential comparison of the goal theme "to be more responsible for myself..." and the SWEMWBS item "I've been feeling useful" as a potential comparison of the goal theme "feeling more confident...". However, neither was considered enough of a direct comparator without assumptions. This suggests that for the most part, standardised tools could be aligned to young people and families' goal themes, which is the current way many clinicians are selecting and using these tools with young people (CORC, 2015). Some themes could be thought of as more processoriented: 'thinking about me and understanding my past' or 'talking about feelings and thoughts' and are less helpful in indicating appropriate types of help than more outcome-orientated goals such as to 'stop harming myself' or 'do better at school'.

Of the 27 goal themes explored, 7 did not correspond to any item on the standardised tools considered. These findings have implications on a number of fronts. When determining what standardised tool to use, clinicians may want to consider the specific goals the person has set, rather than the nature of difficulties as such. This presents a radical reformulation of how 
these tools should be chosen and used. For example, someone attending with excessive handwashing and severe OCD may agree their goal as "better family relationships". The current way of working would be to measure change in symptoms (potentially alone) but what is suggested is a focus on what is important to them, which may be the family relationships and measuring any change in that area. The intervention may remain CBT for handwashing and you may still be interested in symptom change, but this would be for the purpose of improving relationships: even if the mechanism by which they improve is through work on handwashing. This links to the example of work done already on needs-based groupings and the suggestion that outcome measurement is chosen based on collaborative discussions to determine what is most important to the service user (Wolpert et al., 2015). This would also suggest that training in the use of standardised tools could focus on using goals to guide measurement choices and agreeing with young people and families around this.

However, building on previous research (Weisz et al., 2011; Batty et al., 2012; Jacob et al., 2015) these findings suggest that there are outcome areas that young people and families find important that are not explored by existing commonly used tools. These areas include more proximal, existential factors such as understanding difficulties, letting people know what help they need, feeling able to talk about things, thinking things through, feeling more confident and talking about thoughts and feelings. This raises a number of issues. Due to this lack of coverage of standardised tools matched to themes identified by goal themes, we may need to develop or look for new tools that capture these areas. In other countries (e.g., North America) there are established measures for targeting not only the focus of treatment but also the tools used to track treatment progress (i.e., Top Problems; Weisz et al., 2011). The findings of the present research provide a framework for clinicians in the UK to select outcome measures and clinical feedback tools based on goals that have been set, enabling them to personalise care and outcomes within widely used models of routine outcome measurement (CORC; Fleming et al., 2014; CYP IAPT; Law \& Wolpert, 2014).

As discussed, available standardised measurement for areas such as coping and understanding are either unavailable or not fit for purpose e.g. coping measures based on stress (Causey, \& Dubow, 1992); resilience bound by cultural and contextual understandings (Ungar et al., 2008); and youth empowerment and self-esteem questionnaire items being too broad (Childs, Deighton \& Wolpert, 2013). This also leads to the question of whether clinicians need to have more explicit conversations with young people and families about what services are there for. For example, is it ever appropriate for a goal to be to understand something, or is it only appropriate for understanding to be a by-product or a mechanism of the goal? Consequently, it is important to continue to consider goals as measurement alongside other tools to ensure a breadth of information is captured (Law \& Jacob, 2015). 


\section{Limitations}

The goals initially analysed were an approximation of a wider clinical conversation; the richness of which was unlikely to have been transferred to the goal description. We cannot be sure of how consistently goals were recorded; some may be very high-level goals, while others may record more specific goals. It also means that the accuracy of the goal content cannot be easily verified. Other research based on a similar dataset suggested that there is a high proportion of missing goals data at the outset of therapy from routinely collected information (Wolpert et al., 2012). However, the present dataset was fairly large, and from varied types of services which is positive in terms of sample selection and generalisability, although the effects of the self-selecting sample are unknown.

The themes used for the present research have not been validated any further than the initial conception study, which has implications on how they can be used in further research. However, in the initial research, the coders did obtain good interrater reliability, which is encouraging. As discussed elsewhere (Jacob et al., 2015) the nature of how the data were collated resulted in the inability to link all data to demographic information. Therefore, the analysis was not broken down by age, but some of the standardised tools include age limits for use.

\section{Conclusion}

We present a fundamental reformulation of how outcome and feedback tools should be chosen and used, based on our findings that suggest there is a place for using goals as a way to ensure that all aspects of preferred outcome are covered, which is key to a person-centred focus, leading to better shared decision making and personalised care (Kazdin, 1977; Mulley, Trimble \& Elwyn, 2012)

\section{Clinical implications}

As most of the goals themes matched more than one standardised tool, outcome measurement should be chosen based on collaborative discussions to determine what is most important to the individual. This presents opportunities for more collaboration: suggesting a couple of standardised tools to the young person/family and asking them which one seems to make most sense to them to use to track change in therapy.

When determining which tools to use, clinicians may want to consider the specific goals the person has set, rather than the nature of difficulties. This is a move away from a medical model of outcome measurement that matches tools to diagnosis. 
We may need to develop or look for new tools that capture the areas identified as not currently in scope of the existing commonly used standardised tools.

Further training may be needed to help clinicians collaborate with young people and families to set more clinically helpful goals that give a focus to the work and also point to more appropriate tools to track progress. For example, process-oriented goal themes such as 'talk about feelings and thoughts' might need more clarity to help decide on an appropriate intervention: a young person may feel that talking about feelings and thoughts might help them feel less depressed (outcome goal); this may be more helpful to focus the work and match the goal with an appropriate tool to use. A good analogy is to think about outcome goals as a destination for travel ("I want to go to America") and process goals as the vehicle to get you there ("I want to go by plane"). Process goals are not much use clinically without outcomes goals. "I want to take a plane" (process) because "I want to go to America" (outcome).

There is a question of whether clinicians need to have more explicit conversations with young people and families about what services are there for (particularly publicly or insurance funded). The THRIVE model (Wolpert et al., 2015) sets out five areas of need or care that goals may fit into: Thriving (having none or very minor current problems); Coping (having difficulties that pose low risk and the family choose to 'cope' without further direct treatment); Getting Help (the family want treatment and there is a good evidence-based intervention that fits with the family's goals); Getting More Help (longer-term or more intensive treatment is needed to help reach a goal), and Risk Support (the young person has difficulties that present high risk but no suitable treatment is available, either because the young person chooses not to engage with treatment or none is available). A good goal-focused first assessment or choice appointment (CAPA; York \& Kingsbury, 2013) can help match the family with the right area of care based on their goals as well as match the goal to a standardised tool.

Finally, the suggestion is to continue to consider goals as both useful clinical feedback tools and outcome measurement alongside other standardised tools to ensure a breadth of information.

\section{Acknowledgements}

The authors would also like to thank all members of CORC; the Committee at the time of writing (including M.W. \& D.L): Ashley Wyatt, Julie Elliott, Ann York, Mick Atkinson, Tamsin Ford, Alan Ovenden and Kate Martin; the CORC team at the time of writing (including J.J.): Matt Barnard, Elisa Napoleone, Victoria Zamperoni, Lily Levy, Charlotte Payne, Kallum 
Rogers, Slavi Savic, Kate Dalzell, Sally Marriott, Alison Ford, Craig Hamilton and Deborah Sheppard; and Amy EllisThompson and Izzi Whelan.

\section{Declaration of conflicting interests}

Duncan Law and Jenna Jacob have produced guidance on the use of goals. Miranda Wolpert and Duncan Law currently work as part of CORC and the CYP IAPT programme, which encourages the use of goal-based measures.

\section{Funding}

This research received no specific grant from any funding agency in the public, commercial or not-for-profit sectors.

\section{References}

Alderson, P., Sutcliffe, K., \& Curtis, K. (2006). Children as partners with adults in their medical care. Archives of Disease in Childhood, 91, 300-303.

Asarnow, J., Jaycox, L., Tang, L., Duan, N., LaBorde, A., Zeledon, L., . . Wells, K. (2009). Long-term benefits of short-term quality improvement interventions for depressed youths in primary care. The American Journal of Psychiatry, 166, 10021010.

Badham, B. (2011). Talking about talking therapies: thinking and planning about how to make good and accessible talking therapies available to children and young people. Retrieved from http://www.iapt.nhs.uk/silo/files/talking-about-talkingtherapies.pdf

Batty, M., Moldavsky, M., Fouroushani, P., Pass, S., Marriott, M., Sayal, K. \& Hollis, C. (2012). Implementing routine outcome measures in child and adolescent mental health services: from present to future practice. Child and Adolescent Mental Health, 18, 82-87.

Beck, A. T. (1997) The past and future of cognitive therapy. Journal of Psychotherapy Practice and Research, 6, 276-284. 
Bickman, L., Kelley, S., Breda, C., de Andrade, A., \& Riemer, M. (2011). Effects of routine feedback to clinicians on mental health outcomes of youths: Results of a randomized trial. Psychiatric Services, 62, 1423-1429.

Bradley, J., Murphy, S., Fugard, A., Nolas, S., \& Law, D. (2013). What kinds of goals do children and young people set for themselves in therapy? Developing a goals framework using CORC data. Child \& Family Clinical Psychology Review, 1, 818.

Braun, V. \& Clarke, V. (2006). Using thematic analysis in psychology. Qualitative Research in Psychology, 3, 77-101.

Bromley, C. \& Westwood, S. (2013). Young people's participation: views from young people on using goals. Clinical and Family Psychology Review, 1, 41-60.

Boswell, J., Kraus, D., Miller, S., \& Lambert, M. (2015). Implementing routine outcome monitoring in clinical practice: Benefits, challenges, and solutions. Psychotherapy Research, 25, 6-19.

Carlier, I., Meuldijk, D., Van Vliet, I., Van Fenema, E., Van der Wee, N., \& Zitman, F. (2012). Routine outcome monitoring and feedback on physical or mental health status: evidence and theory. Journal of Evaluation in Clinical Practice, 18, 104110.

Causey, D., \& Dubow, E. (1992). Development of a self-report coping measure for elementary school children. Journal of Clinical Child and Adolescent Psychology, 21, 47-59.

Chewning, B., Bylund, C. L., Shah, B., Arora, N. K., Gueguen, J. A., \& Makoul, G. (2012). Patient preferences for shared decisions: a systematic review. Patient education and counseling, 86(1), 9-18.

Childs, J., Deighton, J. \& Wolpert, M. (2013). Defining and measuring mental health and wellbeing in children: a response mode report requested by the Department of Health for the Policy Research Unit in the Health of Children, Young People and Families: Project report. Retrieved from:

https://www.ucl.ac.uk/ebpu/docs/publication_files/Defining_and_measuring_mental_health_and_wellbeing_in_children-

\section{CPRU_RM_report.pdf}

Cooper, M. (2008). The facts are friendly. Therapy Today, 19, 8-13. 
CORC (2015). http://www.corc.uk.net/ Accessed on August 62015.

Corbin, J. M., \& Strauss, A. (1990). Grounded theory research: Procedures, canons, and evaluative criteria. Qualitative Sociology, 13, 3-21.

Coyne, I. (2006). Consultation with children in hospital: children, parents' and nurses' perspectives. Journal of Clinical Nursing, 15, 61-71.

de Jong, K. (2014). Deriving implementation strategies for outcome monitoring feedback from theory, research and practice. Administration and Policy in Mental Health and Mental Health Services Research, 1-5.

de Jong, K., van Sluis, P., Nugter, M. A., Heiser, W. J., \& Spinhoven, P. (2012). Understanding the differential impact of outcome monitoring: Therapist variables that moderate feedback effects in a randomized clinical trial. Psychotherapy Research, 22, 464-474.

Department of Health (2010). Equity and excellence: liberating the NHS. London, UK: The Stationery Office Ltd. Retrieved from https://www.gov.uk/government/uploads/system/uploads/attachment_data/file/213823/dh_117794.pdf

Department of Health. (2011). No Health Without Mental Health. London, UK: HM Government. Retrieved from https://www.gov.uk/government/uploads/system/uploads/attachment_data/file/213761/dh_124058.pdf

Department of Health (2015). Future in mind: Promoting, protecting and improving our children and young people's mental health and wellbeing. London, UK: NHS England. Retrieved from https://www.gov.uk/government/uploads/system/uploads/attachment_data/file/414024/Childrens_Mental_Health.pdf

Diamond, G. M., Liddle, H. A., Hogue, A. \& Dakof, G. A. (1999) Alliance-building interventions with adolescents in family therapy: a process study. Psychotherapy, 36 (4) 355-368.

Dogra, N. (2005). What do children and young people want from mental health services? Current Opinion in Psychiatry, 18, $370-373$. 
Edbrooke-Childs, J., Jacob, J., Law, D., Deighton, J., \& Wolpert, M. (2015). Interpreting standardized and idiographic outcome measures in CAMHS: what does change mean and how does it relate to functioning and experience? Child and Adolescent Mental Health. Online first.

Edbrooke-Childs, J., Wolpert, M., \& Deighton, J. (2014). Using Patient Reported Outcome Measures to Improve Service Effectiveness (UPROMISE): Training clinicians to Use Outcome Measures in Child Mental Health. Administration and Policy in Mental Health and Mental Health Services Research. Online first.

Emanuel, R., Catty, J., Anscombe, E., Cantle, A., \& Muller, H. (2013). Implementing an aim-based outcome measure in a psychoanalytic child psychotherapy service: Insights, experiences and evidence. Clinical Child Psychology and Psychiatry, 19,169-83.

Fleming, l., Jones, M., Bradley, J., \& Wolpert, M. (2014). Learning from a learning collaboration: The CORC approach to combining research, evaluation and practice in child mental health. Administration and Policy in Mental Health and Mental Health Services Research. Online first.

Frueh, B. C., Ford, J. D., Elhai, J.D. \& Grubaugh, A.L. (2012). Evidence-based practice in adult mental health. In P. Sturmy, \& M. Hersen (Eds.), Handbook of Evidence-based Practice in Clinical Psychology, Volume Il: Adult disorder (pp.3-14) Hobeken, NJ: John Wiley \& Sons.

Glaser, B. S., \& Strauss, A. (1967). The Discovery of Grounded Theory. In A.L. Strauss \& J.M. Corbin (1990). Basics of Qualitative Research: Vol. 15. Newbury Park, CA: Sage.

Gollwitzer, P.M. \& Moskowitz, G.B. (1996) Goal effects on action and cognition. Social psychology: handbook of basic principles. New York: Guilford. pp. 361-399.

Gresham, F. M., \& Lopez, M. F. (1996). Social validation: A unifying concept for school-based consultation research and practice. School Psychology Quarterly, 11(3), 204.

Grosse Holtforth, M. \& Grawe, K. (2002). Bern Inventory of treatment goals: Part 1: Development and First Application of a Taxonomy of Treatment Goal Themes. Psychotherapy Research, 12, 79-99. 
Gyamfi, P., Keens-Douglas, A., \& Medin, E. (2007). Youth and youth coordinators' perspectives on youth involvement in systems of care. The Journal of Behavioral Health Services \& Research, 34, 382-394.

Hall, C. L., Moldavsky, M., Taylor, J., Sayal, K., Marriott, M., Batty, M. J., ... \& Hollis, C. (2014). Implementation of routine outcome measurement in child and adolescent mental health services in the United Kingdom: a critical perspective. European Child \& Adolescent Psychiatry, 23, 239-242.

Hannan, C., Lambert, M. J., Harmon, C., Nielsen, S. L., Smart, D. W., Shimokawa, K., \& Sutton, S. W. (2005). A lab test and algorithms for identifying clients at risk for treatment failure. Journal of Clinical Psychology, 61, 155-163.

Hawley, K. M., \& Weisz, J. R. (2005). Youth versus parent working alliance in usual clinical care: Distinctive associations with retention, satisfaction, and treatment outcome. Journal of Clinical Child and Adolescent Psychology, 34, 117-128.

The Health Foundation. (2012). Evidence: Helping people share decision making. London, England: Health Foundation. Retrieved from http://www.health.org.uk/sites/default/files/HelpingPeopleShareDecisionMaking.pdf House of Commons Health Committee (2014). Children's and adolescents' mental health and CAMHS: Third Report of Session 2014-15. London, UK: The Stationery Office Ltd.

Huffine, C. (2005). Supporting recovery for older children and adolescents. Focal Point: Research, Policy and Practice in Children's Mental Health, 19, 22-24.

Institute of Medicine. (2001). Crossing the quality chasm: A new health system for the 21st Century. Washington, DC: National Academy Press.

Kazdin, A. E. (1977). Assessing the clinical or applied importance of behavior change through social validation. Behavior Modification, 1(4), 427-452.

Kelsey, J., Abelson-Mitchell, N., \& Skirton, H. (2007). Perceptions of young people about decision making in the acute healthcare environment. Paediatric Nursing, 19, 14-18. 
Kiresuk, T.J. \& Sherman, R.E. (1968). Goal attainment scaling: a general method for evaluating comprehensive community mental health programs. Community Mental Health Journal, 4, 443-453.

Lambert M. (2010). Yes, it is time for clinicians to routinely monitor treatment outcome; In B.L. Duncan, S.D. Miller, B.E. Wampold et al. (Eds). The Heart and Soul of Change (2nd ed). Washington, DC: American Psychological Association.

Lambert, M., Whipple, J., Hawkins, E., Vermeersch, D., Nielsen, S., \& Smart, D. (2003). Is it Time for Clinicians to Routinely Track Patient Outcome? A Meta-Analysis. Clinical Psychology: Science and Practice, 10(3), 288-301.

Law, D. \& Jacob, J. (2015). Goals and Goals Based Outcomes (GBOs): Some useful information (3RD ed). London, UK: CAMHS Press.

Law, D., \& Wolpert, M. (2014). Guide to Using Outcomes and Feedback Tools with Children, Young People and Families, London, UK: CAMHS Press.

Liberman, R. P., \& Kopelowicz, A. (2002). Teaching people with severe mental disabilities to be their own case managers. Psychiatric Services, 53, 1377-1379.

McGinnity, A., Meltzer, H., Ford, T., \& Goodman, R. (2005). Mental health of children and young people in Great Britain, 2004. Basingstoke, UK: Palgrave Macmillan.

Moran, P., Kelesidi, K., Guglani, S., Davidson, S. \& Ford, T. (2012). What do parents and carers think about routine outcome measures and their use? A focus group study of CAMHS attenders. Clinical Child Psychology and Psychiatry, 17, 65-79.

Mulley, A., Trimble, C., \& Elwyn, G. (2012). Stop the silent misdiagnosis: patients; preferences matter. BMJ, 345, e6572.

NHS. (2015). Governance Arrangements for Research Ethics Committees (GAfREC) Retrieved from http://www.hra.nhs.uk/resources/research-legislation-and-governance/governance-arrangements-for-research-ethics$\underline{\text { committees/ }}$ 
Norman, S., Dean, S., Hansford, L., \& Ford, T. (2013). Clinical practitioner's attitudes towards the use of routine outcome monitoring within child and adolescent mental health services: A qualitative study of two child and adolescent mental health services. Clinical Child Psychology and Psychiatry, 19, 576-95.

O'Brien, M., Crickard, E., Rapp, C., Holmes, C., \& McDonald, T. (2011). Critical issues for psychiatric medication shared decision making with youth and families. Families in Society: The Journal of Contemporary Social Services, 92, 310-316.

Pender, F., Tinwell, C., Marsh, E. \& Cowell, V. (2013). Evaluating the use of goal-based outcomes as a single patient rated outcome measure across CWP CAMHS: a pilot study. Child and Family Clinical Psychology Review, 1, 29-40.

Reid, M. J., Webster-Stratton, C. \& Beauchaine, T. P. (2001) Parent training in head start: a comparison of program response among African American, Asian American, Caucasian and Hispanic mothers. Prevention Science, 2 (4) 209-227.

Reuben, D. B., \& Tinetti, M. E. (2012). Goal-oriented patient care-an alternative health outcomes paradigm. New England Journal of Medicine, 366, 777-779.

Richter, J., Halliday, S., Grømer, L. I., \& Dybdahl, R. (2009). User and carer involvement in child and adolescent mental health services: a Norwegian staff perspective. Administration and Policy in Mental Health and Mental Health Services Research, 36, 265-277.

Riemer, M., \& Bickman, L. (2011). Using program theory to link social psychology and program evaluation. In M.M. Mark, S.I. Donaldson, B. Campbell (Eds). Social Psychology and Evaluation. Guildford, NY: The Guildford Press.

Ruble, L., McGrew, J. H. \& Toland, M. D. (2012). Goal attainment scaling as an outcome measure in randomized control trials of psychosocial interventions in autism. Journal of Autism and Developmental Disorders, 42, 1974-1983.

Sapyta, J., Riemer, M., \& Bickman, L. (2005). Feedback to clinicians: Theory, research, and practice. Journal of Clinical Psychology, 61, 145-153.

Scott, S., Knapp, M., Henderson, J., \& Maughan, B. (2001). Financial cost of social exclusion: follow up study of antisocial children into adulthood. BMJ, 323, 191. 
Shimokawa, K., Lambert, M. J., \& Smart, D. W. (2010). Enhancing treatment outcome of patients at risk of treatment failure: meta-analytic and mega-analytic review of a psychotherapy quality assurance system. Journal of Consulting and Clinical Psychology, 78, 298.

Soffe, J., Read, J., \& Frude, N. (2004). A survey of clinical psychologists' views regarding service user involvement in mental health services. Journal of Mental Health, 13, 583-592.

Ungar, M., Liebenberg, L., Boothroyd, R., Kwong, W. M., Lee, T. Y., Leblanc, J., ... \& Makhnach, A. (2008). The study of youth resilience across cultures: Lessons from a pilot study of measurement development. Research in Human Development, 5, 166-180.

Weisz, J. R., Chorpita, B. F., Frye, A., Ng, M. Y., Lau, N., Bearman, S. K., ... \& Hoagwood, K. E. (2011). Youth Top Problems: using idiographic, consumer-guided assessment to identify treatment needs and to track change during psychotherapy. Journal of Consulting and Clinical Psychology, 79, 369.

Westermann, G., Verheij, F., Winkens, B., Verhulst, F., \& Van Oort, F. (2013). Structured shared decision-making using dialogue and visualization: a randomized controlled trial. Patient education and counseling, 90, 74-81.

Whipple, J., Lambert, M., Vermeersch, D., Smart, D., Nielsen, S., \& Hawkins, E. (2003). Improving the effects of psychotherapy: The use of early identification of treatment and problem-solving strategies in routine practice. Journal of Counseling Psychology, 50, 59.

Windle, G., Bennett, K., \& Noyes, J. (2011). A methodological review of resilience measurement scales. Health and Quality of Life Outcomes, 9, 1-18.

Wolpert, M. (2013). Do patient reported outcome measures do more harm than good? BMJ, 346.

Wolpert, M., Curtis-Tyler, K., \& Edbrooke-Childs, J. (2014). A qualitative exploration of patient and clinician views on patient reported outcome measures in child mental health and diabetes services. Administration and Policy in Mental Health and Mental Health Services Research. Online first. 
Wolpert, M., Deighton, J., De Francesco, D., Martin, P., Fonagy, P., \& Ford, T. (2014). From 'reckless' to 'mindful' in the use of outcome data to inform service-level performance management: perspectives from child mental health. BMJ Quality \& Safety. Online first bmjqs-2013.

Wolpert, M., Ford, T., Trustam, E., Law, D., Deighton, J., Flannery, H., et al. (2012)1. Patient-reported outcomes in child and adolescent mental health services (CAMHS): Use of idiographic and standardized measures. Journal of Mental Health, 21, $165-173$.

Wolpert, M., Fugard, A., Deighton, J., \& Görzig, A. (2012)². Routine outcomes monitoring as part of children and young people's Improving Access to Psychological Therapies (CYP IAPT)-improving care or unhelpful burden? Child and Adolescent Mental Health, 17, 129-130.

Wolpert, M., Harris, R., Hodges, S., Fuggle, P., James, R, Wiener, A., ...Fonagy, P. (2014). THRIVE: The AFC-Tavistock Model for CAMHS. London, UK: CAMHS Press.

Wolpert, M., Vostanis, P., Young, S., Clark, B., Davies, R., Fleming, I., ...Whale, A. (2015). A Guide to Choosing NeedsBased Groupings in Child and Adolescent Mental Health Services to Inform Payment Systems: Version 1. London, UK: CAMHS Press.

Worthen, V., Lambert, M. (2007). Outcome oriented supervision: advantages of adding systematic client tracking to supportive consultations. Counseling and Psychotherapy Research, 7, 48-53.

Yeh, M., \& Weisz, J. (2001). Why Are We Here at the Clinic? Parent-Child (Dis) Agreement on Referral Problems at OutPatient Treatment Entry. Journal of Consulting and Clinical Psychology, 69, 1018-1025.

York, A., \& Kingsbury, S. (2013). Choice and partnership approach: Service transformation model. London, UK: CAMHS Network. 